\title{
Contrast sensitivity and glare disability by halogen light after monofocal and multifocal lens implantation
}

\author{
Sabine Schmitz, H Burkhard Dick, Frank Krummenauer, Oliver Schwenn, Romano Krist
}

\begin{abstract}
Background-Standard examination of contrast sensitivity under conditions of glare disability is performed with incandescent light. A new halogen glare test that simulates glare as seen with oncoming vehicle headlights was used to measure glare disability in patients implanted with multifocal and monofocal intraocular lenses (IOLs).

Methods-28 patients with an average age of 69 years (SD 12 years) were implanted with a monofocal IOL (SI-40NB, Allergan) and 28 patients with an average of 66 years (12 years) were implanted with a refractive multifocal IOL (Array-SA-40N, Allergan). All patients were followed for 5 months postoperatively. Contrast sensitivity at four spatial frequencies $(3,6,12$, and 18 cycles per degree, cpd) with and without a glare source were measured using the halogen glare test (CSV-1000 HGT). Statistical analysis was performed using the two sample Wilcoxon test. The local significance level was set at 0.05 .
\end{abstract}

Results-When tested at the lowest spatial frequency $(3 \mathrm{cpd})$ without halogen glare, contrast sensitivity was lower in the multifocal group than in the monofocal group $(p=0.0292)$. With additional glare, there was no difference between both groups. At all other spatial frequencies (6, 12 , and $18 \mathrm{cpd}$ ), when tested without halogen glare $(6 \mathrm{cpd}, \mathrm{p}=0.5250 ; 12 \mathrm{cpd}$, $\mathrm{p}=0.8483 ; 18 \mathrm{cpd}, \mathrm{p}=0.9496)$ and with moderate (3 cpd, $p=0.7993 ; 6$ cpd, $\mathrm{p}=0.4639 ; 12 \mathrm{cpd}, \mathrm{p}=0.7456 ; 18 \mathrm{cpd}, \mathrm{p}=1.0)$ and high halogen glare $(3 \mathrm{cpd}, \mathrm{p}=0.1513 ; 6$ cpd, $p=0.2016 ; 12 \mathrm{cpd}, \mathrm{p}=0.3069 ; 18 \mathrm{cpd}$, $p=0.9933)$, there was no statistically significant difference between groups. Patients in both groups of age 70 or older had reduced contrast sensitivity without halogen glare and with moderate and strong glare. When monofocal and multifocal patients older than 70 years of age were analysed separately, there was no statistically significant difference in contrast sensitivity with and without glare. Astigmatism $>1$ dioptre had no significant influence on contrast sensitivity and glare disability when monofocal and multifocal eyes were compared.

Conclusion-Reduced contrast sensitivity was found in the multifocal group only at the lowest spatial frequency without halogen glare. The monofocal and multifocal groups had no statistically significant dif- ferences in contrast sensitivity with moderate and strong glare. These results suggest no difference in glare disability induced by halogen light similar to oncoming vehicle headlights for patients implanted with monofocal and multifocal IOLs.

(Br F Ophthalmol 2000;84:1109-1112)

Contrast sensitivity testing is becoming widely used as a routine clinical tool. In road traffic at night headlights can increase glare and decrease contrast sensitivity. Therefore, testing has an important role in evaluating the potential night driving ability of motorists. Previous examinations of contrast sensitivity and glare disability were exclusively performed under incandescent light conditions, ${ }^{1-4}$ which cannot imitate modern road traffic situations encountered by patients in their daily lives. In road traffic, glare disability is more commonly produced by halogen headlights. For the first time, the new halogen glare test can simulate glare analogous to oncoming car headlights as seen at night by a halogen light source, thereby allowing quantification of glare disability similar to that which people encounter in their daily lives. Recently, Dick et $a \tilde{l}$ evaluated the conformity of this objective glare test with subjective findings and reports of monofocal and multifocal patients; the latter thus validates the use of the glare and halo test setting.

Patients and methods

In our study we examined contrast sensitivity and glare disability in two populations. The first group contained 28 eyes of 28 patients after implantation of a foldable, monofocal silicone lens (SI-40NB; Allergan, Irvine, CA, USA). The second group consisted of 28 eyes of 28 patients after implantation of a foldable,

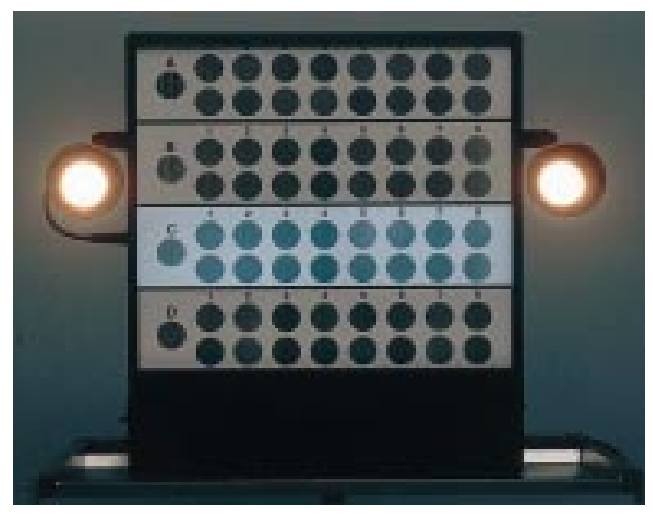

Figure 1 Halogen intraocular lenses glare test CSV-1000HGT at medium glare. 
Table 1 Characteristics of enrolled patients

\begin{tabular}{lll}
\hline & Monofocal $(n=28)$ & Multifocal $(n=28)$ \\
\hline Sex & 20 & 18 \\
$\quad$ Female & 8 & 10 \\
$\quad$ Male & $68.9(12.6)$ & $66.2(11.6)$ \\
Age (years) & $38-88$ & $44-85$ \\
$\quad$ Mean (SD) & & \\
$\quad$ Range & 18 & 15 \\
Eye & 10 & 13 \\
$\quad$ Right & $16.9(0.9)$ & $17.2(0.8)$ \\
$\quad$ Left & $16-18$ & $16-18$ \\
Distance visual acuity (best corrected, $\log$ scale analogon) & \\
$\quad$ Mean (SD) & $21.4(5.4)$ & $15-30$ \\
$\quad$ Range & $11-30$ & $3205(341)$ \\
Time postop (weeks) & & $2500-3600$ \\
$\quad$ Mean (SD) & $3077(390)$ & $0.7(0.4)$ \\
$\quad$ Range & $2400-3700$ & $0.21-1.51$ \\
Pupillary diameter ( $\mu$ m) & & \\
$\quad$ Mean (SD) & $0.9(0.7)$ & \\
$\quad$ Range & $0.02-2.9$ & \\
Astigmatism (D) & Mean (SD) &
\end{tabular}

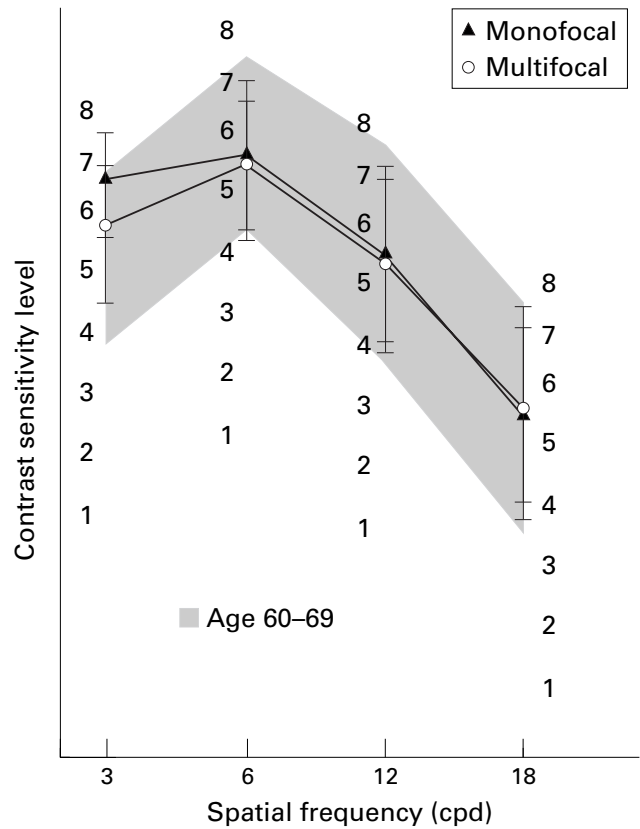

Figure 2 No glare: contrast sensitivity was statistically significantly lower for the multifocal group compared with the monofocal group only at the lowest spatial frequency of 3 cycles per degree (cpd).

silicone, zonal progressive aspheric intraocular lenses (IOL) (Array-SA-40N; Allergan, Irvine, CA, USA). These two three piece foldable IOLs are structurally identical, differing only in the contour of the front surface of the optic. All cataract surgeries were performed by one surgeon who implanted the IOLs into the capsular bag after phacoemulsification through a $3.2 \mathrm{~mm}$ tunnel incision using the Unfolder Silver Series Implantation System (Allergan, Irvine, CA, USA) without any complications. All examinations were performed 5 months postoperatively. The following measurements were completed by a single investigator: computerised videokeratoscopy and measurement of pupil diameter (C-Scan Color Ellipsoid Topography, Technomed, Baesweiler, Germany), visual acuity, slit lamp biomicroscopy of the anterior eye segment in miosis, halogen glare test (Vector Vision, Dayton, $\mathrm{OH}$, USA), slit lamp microscopy of anterior and
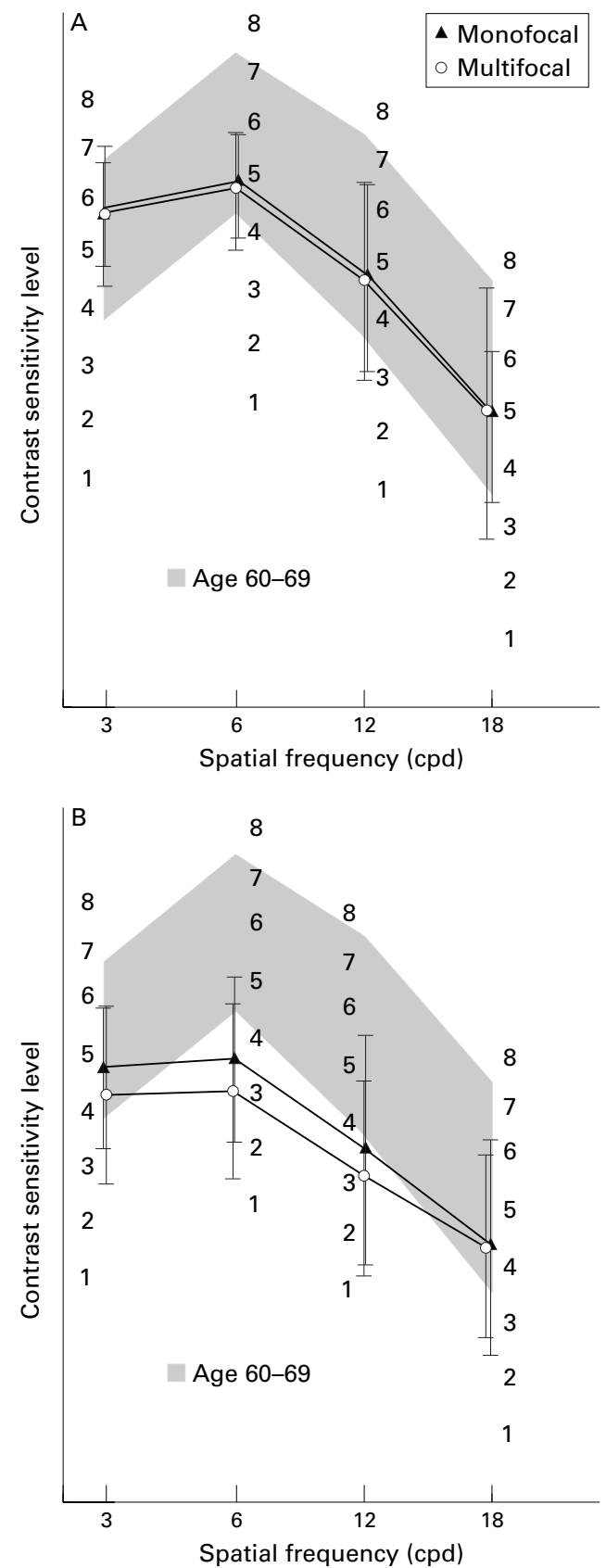

Figure 3 Moderate (A) and high glare (B). No statistically significant difference between both groups at any spatial frequency.

posterior eye segments in mydriasis. Pupil diameter was measured under standardised surrounding illumination conditions. Exclusion criteria included visual acuity $<20 / 25$, IOL decentration $>1 \mathrm{~mm}$, posterior capsule opacification, irregular astigmatism or astigmatism $>1$ dioptre, no active car driving, bad compliance, and retinal diseases (for example, diabetic retinopathy or age related macular degeneration) noted by slit lamp biomicroscopy. Contrast sensitivity and glare disability were examined using the halogen glare test CSV-1000 HGT (Vector Vision, Dayton, OH, USA). The instrument contains four rows with $8 \times 2$ test patterns with decreasing contrast from left to right (Fig 1). The patient is asked to recognise the lines on the top or bottom of 

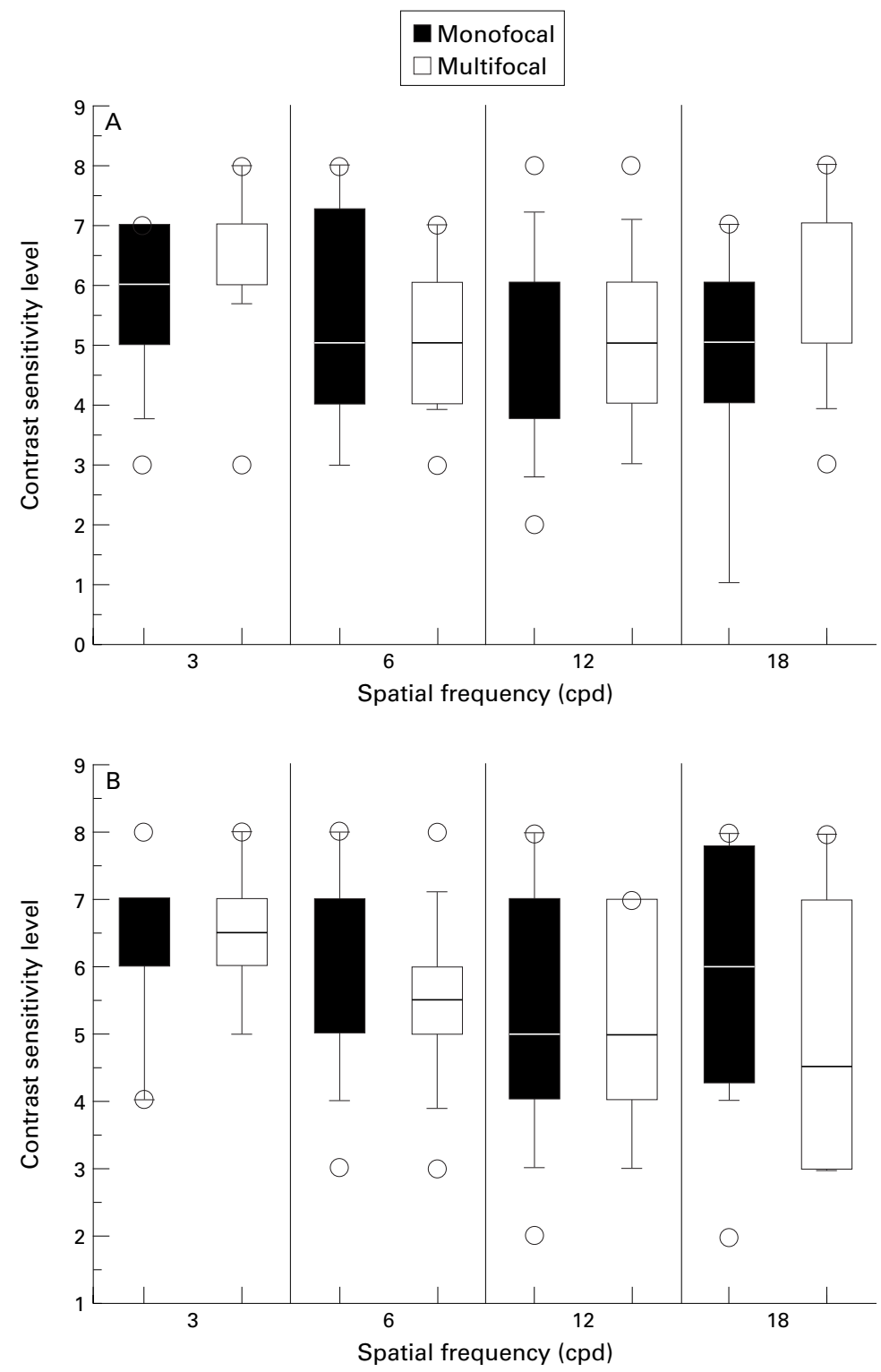

Figure 4 Separate analysis of monofocal versus and multifocal patients younger than 70 years $(A)$ and older than 70 years $(B)$ : no statistically significant difference between both groups within the age groups at any spatial frequency.

the test pattern. The lines encompass four spatial frequencies $(3,6,12$, and 18 cycles per degree, cpd). The halogen light source automatically measures the surrounding illumination and calibrates the instrument's testing light levels. Therefore, it is independent of room illumination. Contrast sensitivity was checked without glare and with moderate as well as with high glare.

\section{STATISTICS}

For statistical analysis, the logarithm of the minimum angle of resolution (logMAR) values of the visual acuity were converted in decimal notation and vice versa as described by Westheimer. ${ }^{6}$ Statistical inference is mainly based on group comparisons (monofocal versus multifocal eyes) following the hypothesis of primary interest of decreased contrast sensitivity and increased glare disability in the multifocal eyes. Statistical significance between the multifocal and monofocal groups was determined by the Wilcoxon test, in which all probability values to be presented in the following were generated using two tailed tests. It was used at an $\alpha$ set at the 0.05 significance level; probability values less than 0.05 thus indicate local significance, and the probability values should be regarded and interpreted as descriptive ones. In an additional analysis, we tried to exclude confounding effects of interaction between lens type and other factors by performing stratified group comparisons for the glare and contrast end points within the multifocal and the monofocal groups, respectively, in which cut off points of astigmatism ( $<1$ dioptre or more) and age ( $<70$ years or older) were defined a priori. Data description is based on means and standard deviations as well as on non-parametric box plots (medians and quartiles). All statistical evaluations were performed using SAS (Release 6.12 for Windows; SAS Institute, Cary, NC), and box plots were generated using STATVIEW (Release 4.51; Abacus Concepts, Berkeley, CA, USA).

\section{Results}

In all, 56 eyes of 38 women and 18 men were included in our study. There was no statistically significant difference between age, visual acuity, and astigmatism between the monofocal and multifocal group. The characteristics of both groups are summarised in Table 1 . There was no statistically significant difference in pupil diameter between the monofocal and multifocal group. Without glare, contrast sensitivity was statistically significantly lower for the multifocal group compared with the monofocal group only at the lowest spatial frequency ( 3 cpd; $p=0.027$, Fig 2). With moderate and high glare, there was no statistically significant difference between both groups at any spatial frequency ( $>>0.05$, Fig 3$)$. When monofocal and multifocal patients older than 70 years were analysed separately, there was no statistically significant difference in contrast sensitivity with and without glare $(\mathrm{p}>0.05$, Fig 4). Thus, increasing age did not affect contrast sensitivity when comparing monofocal and multifocal eyes. However, when monofocal and multifocal eyes were evaluated for within group differences in contrast sensitivity, patients aged 70 years or older had a statistically significant decrease in contrast sensitivity and a significant increase in glare disability $(\mathrm{p}<0.05)$. Astigmatism more than 1 dioptre had no significant influence on contrast sensitivity and glare disability when monofocal and multifocal eyes were compared ( $p>0.05$; Fig 5 ). Table 2 summarises the corresponding Wilcoxon test $p$ values for all variables under consideration.

\section{Discussion}

Contrast sensitivity testing with the addition of glare allows a three dimensional measure of visual function, which can more adequately reflect everyday experience in road traffic compared with measuring visual acuity in a darkened room by traditional methods. In pseudophakic eyes with a clear optical axis, reduced contrast sensitivity and more glare disability have been reported compared with 

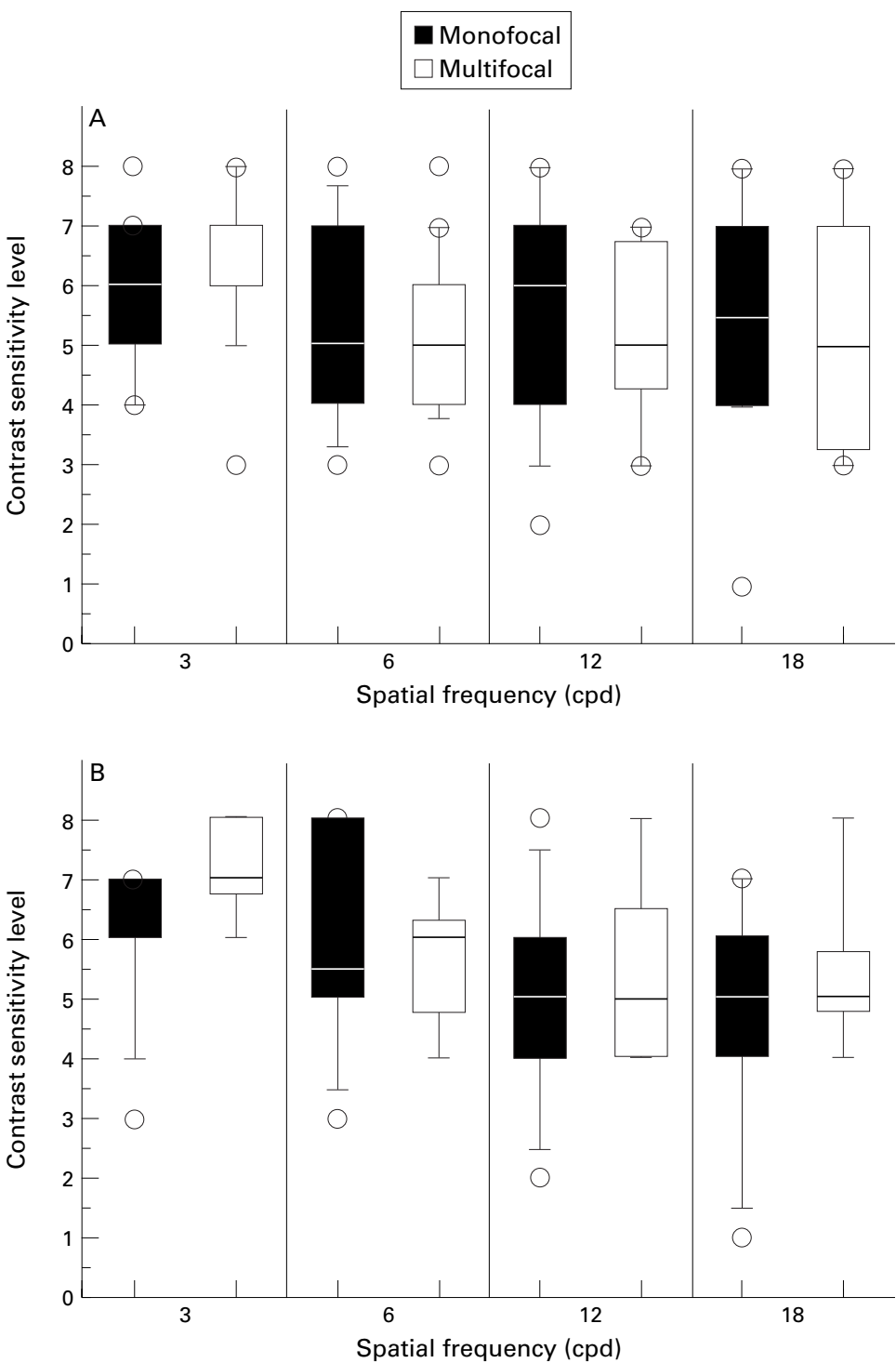

Figure 5 Astigmatism less than 1 dioptre (A) and more than 1 dioptre (B). Greater astigmatism had no statistically significant influence on contrast sensitivity or glare disability when monofocal eyes were compared with multifocal eyes.

Table 2 Wilcoxon p values for lens type comparison

\begin{tabular}{lc}
\hline Spatial frequency without & glare $(c p d)$ \\
3 & 0.0292 \\
6 & 0.5250 \\
12 & 0.8483 \\
18 & 0.9496 \\
Spatial frequency with moderate glare $(c p d)$ \\
3 & 0.7993 \\
6 & 0.4639 \\
12 & 0.7456 \\
18 & 1.000 \\
Spatial frequency with high glare $(c p d)$ \\
3 & 0.1513 \\
6 & 0.2016 \\
12 & 0.3069 \\
18 & 0.9933 \\
\hline
\end{tabular}

eyes with a clear crystalline lens. ${ }^{7}$ In our study we noted a statistically significant difference in contrast sensitivity and glare disability in eyes after monofocal versus multifocal lens implantation only at the lowest spatial frequency of 3 cycles per degree without glare. Inconsistent with theoretical predictions ${ }^{89}$ and our own expectations, both IOL groups achieved comparable results at all other spatial frequencies.
Jacobi and Konen ${ }^{10}$ examined the influence of age and astigmatism on the Array multifocal lens using Regan charts. They showed a decrease in contrast sensitivity and an increase in glare with increasing age. These results were comparable with our results. In our study, monofocal and multifocal patients age 70 or older had a statistically significant decrease in contrast sensitivity and a significant increase in glare disability when evaluated for within group differences. However, astigmatism more than 1 dioptre had no statistically significant influence on contrast sensitivity and glare disability when monofocal and multifocal eyes were compared. These results are supported by Eisenmann and co-workers, ${ }^{2}$ who examined the influence of corneal astigmatism on contrast sensitivity by means of an optical system described by Reiner after physical implantation of monofocal and multifocal IOLs in healthy subjects. ${ }^{211}$ With artificial corneal astigmatism of 2 dioptres or greater contrast sensitivity was below normal range for both monofocal and multifocal IOLs for all spatial frequencies. There was no statistically significant difference between the two lens types. Despite these results glare is expected after implantation of monofocal and multifocal IOLs caused by photoptic phenomena. Increasing age, the corneal surface, and the IOL design seem to have an important role for inducing glare. ${ }^{12}$ Previous examinations of contrast sensitivity with glare were exclusively performed using incandescent light sources.

In our study halogen light for testing glare and contrast sensitivity was used for the first time. By examinating glare disability of pseudophakic eyes using a halogen light source, we were able to simulate conditions that more closely resemble patients' everyday experience-such as those encountered in traffic with oncoming car headlights at night.

1 Arend O, Remky A, Evans D, et al. Contrast sensitivity loss is coupled with capillary dropout in patients with diabetes. is coupled with capillary dropout in patients

2 Eisenmann D, Wagner R, Dick B, et al. Einflu $\beta$ des Hornhautastigmatismus auf die Kontrastempfindlichkeit bei mono- und multifokaler Pseudophakie-eine theoretische Studie am physikalischen Auge. Klin Monatsbl Augenheilkd 1996;209:125-31.

3 Pomerance GN, Evans DW. Test retest reliability of the CSV-1000 contrast test and its relationship to glaucoma therapy. Invest Ophthalmol Vis Sci 1994;35:3357-9.

4 Rüther K, Eisenmann D, Zrenner E, et al. Der Einfluß diffraktiver Multifokallinsen auf Kontrastsehen, Gegenlichtsehschärfe und Farbsinn. Klin Monatsbl Augenheilkd 1994;204:14-19.

5 Dick HB, Krummenauer F, Schwenn O, et al. Objective and subjective evaluation of photic phenomena after monofocal and multifocal intraocular lens implantation. Ophthalmology 1999;106:1878-86.

ogy 1999;106:1878-86.
6 Westheimer G. Scaling of visual acuity measurements. Arch Ophthalmol 1979;97:327-30.

7 Weatherill J, Yap M. Contrast sensitivity in pseudophakia and aphakia. Ophthalmic Physiol Opt 1986;6:297-301.

8 Eisenmann D, Jacobi FK, Dick B, et al. Untersuchungen zur Blendempfindlichkeit phaker und pseudophaker Augen. Klin Monatsbl Augenheilkd 1996;208:87-92.

9 Holladay JT, van Dijk H, Lang A, et al. Optical performance of multifocal intraocular lenses. F Cataract Refract Surg 1990;16:413-22.

10 Jacobi PC, Konen W. Effect of age and astigmatism on the AMO array multifocal intraocular lens. $\mathcal{F}$ Cataract Refract Surg 1995;21:556-61.

11 Eisenmann D, Hessemer V, Manzke B, et al. ModulationsÜbertragungsfunktion und Kontrastempfindlichkeit refraktiver Mehrzonenmultifokallinsen. Ophthalmologe 1993; 90:343-47.

12 Eisenmann D, Jacobi KW. Die ARRAY-MultifokallinseFunktionsprinzip und klinische Ergebnisse. Klin Monatsbl Augenheilkd 1993;203:189-9. 